\title{
Prediksi Estetika, Sikap Terhadap Merek, Dan Persepsi Harga Terhadap Niat Pembelian Iphone
}

\author{
Geraldo Hankho dan Cokki \\ Fakultas Ekonomi dan Bisnis, Universitas Tarumanagara \\ E-mail: ghankho@yahoo.co.id
}

\begin{abstract}
Currently the number of smartphone users has increased over time, where the iPhone is one of Apple's most popular devices. The purpose of this study was to examine whether aesthetics, brand attitude, and perceived price were positive predictors of iPhone purchase intention at Tarumanagara University Faculty of Economics and Business students. This study used 100 samples selected using convenience sampling techniques, where the selected sample were students of the Faculty of Economics and Business at Tarumanagara University who had used an iPhone. The data collection technique was carried out using a questionnaire. Data were analyzed using PLS-SEM. The results of this study indicate that brand attitude, and perceived price are positive predictors of purchase intention, while aesthetics are not positive predictors of purchase intention.
\end{abstract}

Keywords: Aesthetics, Brand Attitude, Perceived Price, Purchase Intention

Abstrak: Saat ini jumlah pengguna smartphone semakin meningkat seiring berjalannya waktu, dimana iPhone merupakan salah satu perangkat Apple yang paling populer. Tujuan penelitian ini adalah untuk menguji apakah estetika, sikap terhadap merek, dan persepsi harga merupakan prediktor positif untuk niat pembelian iPhone pada mahasiswa Fakultas Ekonomi dan Bisnis Universitas Tarumanagara. Penelitian ini menggunakan 100 sampel yang dipilih dengan menggunakan teknik convenience sampling, dimana sampel yang dipilih adalah mahasiswa Fakultas Ekonomi dan Bisnis Universitas Tarumanagara yang pernah menggunakan iPhone. Teknik pengambilan data dilakukan dengan menggunakan kuesioner. Data dianalisis dengan menggunakan PLS-SEM. Hasil penelitian ini menunjukkan bahwa sikap terhadap merek, dan persepsi harga merupakan prediktor positif untuk niat pembelian, sedangkan estetika bukan merupakan prediktor positif untuk niat pembelian.

Kata Kunci: Estetika, Sikap terhadap Merek, Persepsi Harga, Niat Pembelian

\section{LATAR BELAKANG}

Seiring berjalannya waktu, semakin banyak orang yang menggunakan smartphone, dimana kita sering menjumpai orang yang menggunakan smartphone dimanapun dan kapanpun. Smartphone menjadi bagian penting dalam kehidupan sehari hari, dimana smartphone merupakan perangkat yang memiliki fitur serba guna, seperti telepon, sms, chatting, internet, main game, dan fitur fitur lainnya. Seiring berjalannya waktu, jumlah pengguna smartphone mengalami kenaikan setiap tahunnya. Tingkat pengguna smartphone akan naik sesuai dengan permintaan pasar seiring berkembangnya teknologi dengan banyaknya fitur yang ditawarkan (Ting et al., 2011). 
Apple merupakan salah satu perusahaan teknologi informasi ternama di dunia yang mampu bersaing dengan kompetitor lainnya (Gibbs, 2018). Perusahaan Apple mampu bersaing dengan kompetitor yang lainnya, meskipun pada tahun 2019 kuartal kedua Apple sedang mengalami penurunan, akan tetapi perusahaan Apple mencatat keberhasilan melewati perkiraan target, dan penjualan Apple di China mengalami kenaikan (Reuters, 2019).

iPhone merupakan salah satu produk apple yang laris dipasaran. Apple merilis produk iPhone model generasi pertama ini yaitu iPhone 3G pada tanggal 29 Juni 2007, dengan iOS baru yang dirilis, dimana iOS tersebut menghadirkan fitur seperti app store dan iTunes pada saat itu. Apple pada saat itu menjual 6,1 juta unit iPhone generasi pertama yaitu iPhone 3G selama lima kuartal (Apple, 2009). Apple iOS adalah sistem operasi nomor dua dengan tingkat pangsa pasar sebesar 26,2\%, tetapi sebanyak 5,5 juta iPhone yang terjual telah membuatnya iPhone menjadi salah satu perangkat tunggal paling populer (Chen, 2010).

Niat pembelian merupakan salah satu faktor yang penting di dalam bidang pemasaran, karena niat pembelian akan menjadi dasar dalam suatu keputusan pembelian. Niat pembelian berkaitan dengan kemungkinan bahwa konsumen akan membeli suatu produk (Toufani et al., 2017:321). Menurut Kumala (2012 dalam Prawira \& Yasa, 2014:3644) menyatakan bahwa niat pembelian merupakan instruksi diri konsumen untuk melakukan perencanaan, Appemengambil tindakan-tindakan dan mengambil suatu keputusan untuk melakukan pembelian atas suatu produk.

Estetika dapat mempengaruhi niat pembelian secara langsung (Toufani et al., 2017:322). Estetika melibatkan daya tarik visual yang dirasakan dari suatu produk. Estetika merupakan komponen penting dari desain produk, karena dapat meningkatkan daya tarik visual dari suatu produk (Kim et al., 2011:230).

Sikap terhadap merek merupakan salah satu faktor yang dapat mempengaruhi niat pembelian. Sikap terhadap merek adalah penentu paling penting dari niat pembelian (Kudeshia \& Kumar, 2017:317). Jadi konsumen cenderung membeli produk dari suatu merek ketika mereka memiliki sikap yang baik dalam mengevaluasi suatu merek. Sikap terhadap merek menganggap evaluasi merek dapat memberikan kontribusi pada pembentukan niat pembelian. Dengan demikian, sikap terhadap merek memainkan peran penting dalam memprediksi niat pembelian (Park et al., 2015:93).

Persepsi harga merupakan salah satu variabel penting dalam pemasaran. Persepsi harga adalah faktor yang secara positif dapat mempengaruhi niat pembelian yang menunjukkan bahwa harga yang dapat diterima dan sesuai dapat meningkatkan niat untuk pembelian suatu produk. Persepsi harga dapat mempengaruhi niat pembelian, karena konsumen mempertimbangkan harga dalam niat membeli pada produk tertentu, dimana persepsi harga seseorang akan mempengaruhi niat beli seseorang (Ivoni et al., 2015:900).

\section{KAJIAN TEORI}

Niat Pembelian. Semakin banyak jenis produk smartphone yang dipasarkan di Jakarta pada saat ini, membuat para produsen terpacu untuk membuat suatu inovasi dan mengimplementasikan strategi-strategi untuk mendapatkan konsumen baru, mempertahankan konsumen yang sudah ada, dan memenangkan persaingan di pasar. Berdasarkan hal tersebut, maka analisis mengenai niat pembelian sangat penting dilakukan oleh para produsen. Niat pembelian bisa menjadi dasar keputusan dalam pembelian suatu 
produk. Niat pembelian dapat dipengaruhi oleh faktor eksternal maupun internal. Beberapa faktor yang dapat mempengaruhi niat pembelian adalah estetika, sikap terhadap merek, dan persepsi harga. Niat pembelian dapat didefinisikan sebagai kecenderungan konsumen untuk membeli produk atau jasa tertentu di masa yang mendatang (Naing \& Chaipoopirutana, 2014; Ibrahim et al., 2013; Semuel \& Lianto, 2014).

Estetika. Estetika dapat didefinisikan sebagai daya tarik yang dimiliki suatu produk yang dapat menciptakan pertimbangan pribadi dari sisi desain, warna, bentuk, tekstur/sentuhan, dan keindahan (Wang et al., 2011; Santoso, 2014; Nurtjahjanti, 2012; Swilley, 2012). Penelitian yang dilakukan oleh Toufani et al. (2017) menyatakan bahwa estetika memiliki pengaruh positif terhadap niat pembelian. Penelitian yang dilakukan oleh Toufani et al. (2017) sejalan juga dengan penelitian yang dilakukan oleh Kim et al. (2011) dan Ho \& Wu (2012) yang menyatakan bahwa estetika memiliki pengaruh positif untuk niat pembelian. Semakin baik daya tarik yang dimiliki oleh suatu produk, maka probabilitas untuk membeli suatu produk juga akan meningkat.

$\mathbf{H}_{1}$ : Estetika merupakan prediktor positif untuk niat pembelian

Sikap terhadap Merek. Sikap terhadap merek adalah evaluasi keseluruhan konsumen terhadap suatu merek dalam hal kualitas dan kepuasan yang dirasakan oleh konsumen (Ghorban, 2012; Park et al., 2015; Wu \& Wang, 2011). Penelitian yang dilakukan oleh Ghorban (2012) menyatakan bahwa sikap terhadap merek memiliki pengaruh yang positif terhadap niat pembelian. Penelitian yang dilakukan oleh Ghorban (2012) sejalan juga dengan penelitian yang dilakukan oleh Kudeshia \& Kumar (2017) dan Park et al. (2015) menyatakan bahwa sikap terhadap merek memiliki pengaruh positif terhadap niat pembelian. Minat beli suatu produk juga akan semakin tinggi apabila sikap konsumen terhadap suatu merek itu baik dari segi atribut dan manfaat spesifik dari suatu merek tersebut.

H2: Sikap terhadap merek merupakan prediktor positif untuk niat pembelian

Persepsi Harga. Persepsi harga merupakan persepsi mengenai jumlah harga yang ditawarkan terhadap manfaat yang diperoleh (Sumaedi et al., 2011; Zietsman et al., 2019; Ha \& Yoon, 2012). Penelitian yang dilakukan oleh Prawira \& Yasa (2014) menunjukkan bahwa persepsi harga memiliki pengaruh positif terhadap niat pembelian. Penelitian ini sejalan dengan penelitian yang dilakukan oleh Ivoni et al. (2015) dan Lien et al. (2015) yang menyatakan bahwa persepsi harga memiliki pengaruh positif untuk niat pembelian. Semakin baik persepsi konsumen tentang pengorbanan terhadap manfaat yang diperoleh, maka dapat meningkatkan minat konsumen dalam membeli suatu produk tersebut.

$\mathrm{H}_{3}$ : Persepsi harga merupakan prediktor positif untuk niat pembelian

\section{METODOLOGI}

Sampel pada penelitian ini adalah sebanyak 121 mahasiswa fakultas ekonomi dan bisnis Universitas Tarumanagara (FEB UNTAR) yang pernah menggunakan iPhone, dengan convenience sampling, dimana pada penelitian ini sampel yang diteliti adalah responden yang pernah menggunakan iPhone. Pada penelitian ini, desain penelitiannya adalah desain penelitian deskriptif, dimana penelitian ini dilakukan dalam satu kali saja. Instrumen pada penelitian ini dengan menggunakan kuesioner. Pada kuesioner, terdapat 27 butir indikator yang terdiri dari 7 butir indikator untuk variabel estetika, 5 butir indikator untuk variabel sikap terhadap merek, 7 butir indikator untuk variabel persepsi harga, dan 8 butir 
pernyataan untuk variabel niat pembelian. Skala yang digunakan pada penelitian ini adalah skala Likert, dimana skala ini dinyatakan dari 1 (tidak setuju) hingga 5 (setuju).

Untuk menganalisis nilai validitas konvergen, digunakan pendekatan Average Variance Extracted (AVE), dimana untuk masing-masing indikator dipersyaratkan nilainya harus > 0,5 untuk model yang baik (Garson, 2016). Untuk menganalisis nilai validitas diskriminan, digunakan pendekatan Heterotrait-Monotrait Ratio (HTMT), dimana nilai Heterotrait-Monotrait Ratio (HTMT) harus < 0,9 untuk memastikan adanya validitas diskriminan antar variabel (Garson, 2016). Untuk menguji nilai reliabilitas indikator, digunakan pendekatan outer loading pada masing masing indikator. Suatu indikator dikatakan reliabel apabila pada indikator tertentu memiliki nilai outer loading $>0,7$ (Garson, 2016). Untuk menguji nilai reliabilitas konsistensi internal, digunakan pendekatan composite reliability pada masing masing variabel. Suatu variabel dapat dinyatakan reliabel apabila memiliki nilai composite reliability > 0,7 (Garson, 2016).

Model regresi yang baik adalah tidak terdapat multikolinieritas. Multikolinearitas dapat menjadi masalah jika toleransi kurang dari 0,20 atau nilai VIF lebih dari 5 (Garson, 2016:76). Menurut Hair et al. (2014) menjelaskan bahwa hasil di atas batas 0,75 terbilang kuat, sedangkan hasil di atas batas 0,50 terbilang sedang, dan hasil di atas batas 0,25 terbilang lemah. Bila nilai $\mathrm{Q}^{2}>0$ menunjukan bahwa model tersebut mempunyai nilai relevansi prediksi, sedangkan nilai $\mathrm{Q}^{2}<0$ menunjukan bahwa model kurang memiliki nilai relevansi prediksi (Hair et al., 2014). Nilai koefisien jalur distandarisasi pada rentang dari 1 hingga +1 , dengan nilai path coefficient yang lebih dekat ke +1 mewakili hubungan positif yang kuat, dan nilai path coefficient yang lebih dekat ke -1 menunjukkan hubungan negatif yang kuat (Hair et al., 2014). Suatu hipotesis dapat dikatakan signifikan apabila $p$ value < 0,05 (Garson, 2016). Menurut Cohen (1988 dalam Garson, 2016:85) menyatakan bahwa hasil di atas batas 0,02 mewakili ukuran efek yang lemah, sedangkan hasil di atas batas 0,15 mewakili ukuran efek yang sedang, dan hasil di atas batas 0,35 mewakili ukuran efek yang kuat. Alat yang digunakan untuk menganalisis data adalah dengan menggunakan PLS-SEM.

\section{HASIL ANALISIS DATA}

Karakterisitik Responden. Berdasarkan jenis kelamin, mayoritas responden merupakan perempuan $(54,5 \%)$, dan sisanya merupakan laki laki (45,5\%). Berdasarkan usia, mayoritas responden berusia 21-23 tahun $(62,8 \%)$, sisanya berusia $18-20$ tahun $(33,9 \%)$ dan lebih dari 23 tahun $(3,3 \%)$. Berdasarkan pengeluaran setiap bulan, mayoritas responden memiliki pengeluaran di atas Rp 1.500 .000 (49,6\%), sisanya memiliki pengeluaran Rp 1.000 .000 - Rp 1.500.000 (33,9\%) dan memiliki pengeluaran di bawah Rp 1.000 .000 $(16,5 \%)$. Dalam penelitian ini, kuesioner disebarkan kepada 121 responden, namun hanya $100(82,6 \%)$ responden yang memenuhi kriteria untuk dijadikan subjek untuk penelitian ini, dimana kriteria tersebut adalah responden pernah mencoba menggunaka iPhone.

\section{Outer Model}

Tabel 1. Hasil Uji Validitas Konvergen

\begin{tabular}{|l|c|}
\hline \multicolumn{1}{|c|}{ Variabel } & AVE \\
\hline Estetika & 0,563 \\
\hline
\end{tabular}




\begin{tabular}{|l|l|}
\hline Sikap terhadap Merek & 0,681 \\
\hline Persepsi Harga & 0,652 \\
\hline Niat Pembelian & 0,679 \\
\hline
\end{tabular}

Berdasarkan hasil analisis validitas konvergen yang diukur dengan pendekatan AVE di atas, dapat di simpulkan bahwa hasil AVE pada semua variabel lebih dari 0,5. Dengan demikian keempat variabel tersebut memenuhi analisis validitas konvergen yang diukur dari AVE (Tabel 1).

Tabel 2. Hasil Uji Validitas Diskriminan

\begin{tabular}{|c|c|c|c|}
\hline & Estetika & Sikap terhadap Merek & Persepsi Harga \\
\hline Estetika & - & - & - \\
\hline Sikap terhadap Merek & 0,752 & - & - \\
\hline Persepsi Harga & 0,496 & 0,394 & - \\
\hline Niat Pembelian & 0,651 & 0,839 & 0,553 \\
\hline
\end{tabular}

Berdasarkan hasil analisis validitas diskriminan yang diukur dengan pendekatan HTMT, dapat disimpulkan bahwa nilai HTMT dari semua hubungan masing masing variabel terhadap variabel lainnya memiliki nilai HTMT $<0,9$, artinya semua hubungan masing masing variabel terhadap variabel lainnya telah memenuhi validitas diskriminan yang diukur dari HTMT (Tabel 2).

Tabel 3. Hasil Uji Reliabilitas Indikator

\begin{tabular}{|c|c|c|}
\hline Indikator & Outer Loading & $\boldsymbol{p}$-value \\
\hline A1 & 0,693 & 0,000 \\
\hline A2 & 0,766 & 0,000 \\
\hline A3 & 0,801 & 0,000 \\
\hline A4 & 0,735 & 0,000 \\
\hline A5 & 0,745 & 0,000 \\
\hline A6 & 0,769 & 0,000 \\
\hline A7 & 0,742 & 0,000 \\
\hline BA1 & 0,854 & 0,000 \\
\hline BA2 & 0,874 & 0,000 \\
\hline BA3 & 0,863 & 0,000 \\
\hline BA4 & 0,704 & 0,000 \\
\hline BA5 & 0,821 & 0,000 \\
\hline PP1 & 0,821 & 0,000 \\
\hline PP2 & 0,738 & 0,000 \\
\hline
\end{tabular}

\begin{tabular}{|c|c|c|}
\hline Indikator & Outer Loading & $\boldsymbol{p}$-value \\
\hline PP3 & 0,723 & 0,000 \\
\hline PP4 & 0,774 & 0,000 \\
\hline PP5 & 0,893 & 0,000 \\
\hline PP6 & 0,843 & 0,000 \\
\hline PP7 & 0,846 & 0,000 \\
\hline PI1 & 0,796 & 0,000 \\
\hline PI2 & 0,848 & 0,000 \\
\hline PI3 & 0,832 & 0,000 \\
\hline PI4 & 0,811 & 0,000 \\
\hline PI5 & 0,833 & 0,000 \\
\hline PI6 & 0,863 & 0,000 \\
\hline PI7 & 0,769 & 0,000 \\
\hline PI8 & 0,838 & 0,000 \\
\hline
\end{tabular}

Berdasarkan hasil analisis reliabilitas indikator yang diukur dengan pendekatan outer loading, dapat disimpulkan bahwa semua indikator memiliki nilai outer loading di atas 0,7. Sehingga dapat memenuhi syarat analisis reliabilitas indikator yang diukur dari nilai outer loading (Tabel 3). 
Tabel 4. Hasil Uji Reliabilitas Konsistensi Internal

\begin{tabular}{|c|c|}
\hline Variabel & Composite Reliability \\
\hline Estetika & 0,900 \\
\hline Sikap terhadap Merek & 0,914 \\
\hline Persepsi Harga & 0,929 \\
\hline Niat Pembelian & 0,944 \\
\hline
\end{tabular}

Berdasarkan hasil analisis reliabilitas konsistensi internal yang diukur dengan pendekatan composite reliability di atas, dapat disimpulkan bahwa pada variabel aesthetics, brand attitude, perceived price, dan purchase intention memiliki nilai composite reliability $>0,7$. artinya bahwa semua variabel memenuhi reliabilitas konsistensi internal yang diukur dengan composite reliability (Tabel 4).

Inner Model

Tabel 5. Hasil Uji Multikolinieritas

\begin{tabular}{|c|c|c|}
\hline Variabel & Nilai & Keterangan \\
\hline $\mathrm{PI}=\mathrm{f}(\mathrm{A}, \mathrm{BA}, \mathrm{PP})$ & & \\
$\mathrm{A}$ & $\mathrm{VIF}=1,991$ & Tidak ada multikolinieritas \\
$\mathrm{BA}$ & $\mathrm{VIF}=1,803$ & Tidak ada multikolinieritas \\
$\mathrm{PP}$ & $\mathrm{VIF}=1,400$ & Tidak ada multikolinieritas \\
\hline
\end{tabular}

Berdasarkan hasil analisis multikolinieritas yang diukur dengan pendekatan VIF inner model, dapat disimpulkan bahwa pada variabel estetika, sikap terhadap merek, dan persepsi harga terhadap niat pembelian memiliki nilai VIF $<5$, artinya pada masing masing variabel tidak terdapat multikolinieritas atau tumpah tindih antar variabel (Tabel 5).

Berdasarkan hasil analisis koefisien determinasi yang diukur dengan pendekatan $R$ square, dapat disimpulkan bahwa nilai $R$ square untuk variabel niat pembelian adalah sebesar 0,660. Artinya sebesar 66,0\% variabel niat pembelian dapat dijelaskan oleh variabel estetika, sikap terhadap merek, dan persepsi harga, sisanya sebesar 34,0\% dapat dijelaskan oleh faktor faktor yang lainnya. Kemampuan estetika, sikap terhadap merek, dan persepsi harga untuk menjelaskan variabel niat pembelian ini terbilang sedang.

Berdasarkan hasil analisis relevansi prediksi yang diukur dengan pendekatan $Q$ square, dapat disimpulkan bahwa hubungan konstruk variabel yang telah diteliti dalam penelitian ini dianggap relevan untuk mengukur model penelitian yang telah terbentuk sebelumnya. Hal ini dapat dilihat dari hasil analisis predictive relevance $\left(\mathrm{Q}^{2}\right)$ dalam penelitian ini, yaitu hasil $Q$ square pada variabel niat pembelian dalam penelitian ini lebih besar dari nol, dimana memiliki nilai $Q$ square sebesar 0,403.

Tabel 6. Hasil Rekapitulasi Pengujian Hipotesis

\begin{tabular}{|l|c|c|c|l|}
\hline \multicolumn{1}{|c|}{ Hipotesis } & $\boldsymbol{\beta}$ & $\boldsymbol{p}$-value & $\mathbf{f}^{\mathbf{2}}$ & \multicolumn{1}{|c|}{ Keterangan } \\
\hline $\mathrm{H}_{1}:$ Estetika $\rightarrow$ Niat Pembelian & 0,072 & 0,154 & 0,008 & Tidak didukung \\
\hline $\begin{array}{l}\mathrm{H}_{2}: \text { Sikap terhadap Merek } \rightarrow \text { Niat } \\
\text { Pembelian }\end{array}$ & 0,616 & 0,000 & 0,618 & Didukung \\
\hline $\mathrm{H}_{3}:$ Persepsi Harga $\rightarrow$ Niat Pembelian & 0,274 & 0,000 & 0,171 & Didukung \\
\hline
\end{tabular}


Pada hasil pengujian hipotesis 1 di atas menunjukkan bahwa estetika merupakan prediktor positif, tetapi tidak signifikan, dan memiliki efek yang tidak berarti untuk niat pembelian. Hal ini menunjukkan bahwa $\mathrm{H}_{1}$ tidak didukung. Pada hasil pengujian hipotesis 2 di atas menunjukkan bahwa sikap terhadap merek merupakan prediktor positif, signifikan, dan memiliki efek yang kuat untuk niat pembelian. Hal ini menunjukkan bahwa $\mathrm{H}_{2}$ didukung. Pada hasil pengujian hipotesis 3 di atas menunjukkan bahwa persepsi harga merupakan prediktor positif, signifikan, dan memiliki efek sedang untuk niat pembelian. Hal ini menunjukkan bahwa $\mathrm{H}_{3}$ didukung (Tabel 6).

\section{DISKUSI}

Pada hasil pengujian hipotesis pertama $\left(\mathrm{H}_{1}\right)$ menunjukkan bahwa estetika bukan merupakan prediktor positif untuk niat pembelian. Hasil pengujian hipotesis ini tidak sejalan dengan penelitian yang dilakukan oleh Toufani et al. (2017), Kim et al. (2011), dan Ho \& Wu (2012) yang menyatakan bahwa estetika merupakan prediktor positif untuk niat pembelian. Tetapi hasil pengujian hipotesis ini sejalan dengan penelitian yang dilakukan oleh Shaharudin et al. (2011) yang menyatakan bahwa estetika bukan merupakan prediktor positif untuk niat pembelian. Estetika sendiri merupakan daya tarik yang dimiliki suatu produk yang dapat menciptakan pertimbangan pribadi dari sisi desain, warna, bentuk, tekstur/sentuhan, dan keindahan. Shaharudin et al. (2011) menyatakan bahwa baik atau buruknya estetika dari suatu produk masih dapat mendorong pelanggan untuk membeli suatu produk. Seperti yang kita tahu, iPhone merupakan salah satu perangkat smartphone yang memiliki desain yang elegan dan merupakan perangkat smartphone yang terkenal, tetapi di jual dengan harga yang tinggi. Salah satu contoh produk iPhone yang dijual dengan harga tinggi pada saat ini adalah iPhone 11 yang dijual dengan harga Rp 12.999.000 hingga Rp 16.199.000, iPhone 11 Pro yang dijual dengan harga Rp 18.499.000 hingga Rp 25.799.000, dan untuk iPhone 11 Pro Max dijual dengan harga Rp 19.999.000 hingga Rp 27.499.000 (Kompas Cyber Media, 2019). Dalam kasus ini, peneliti mengasumsikan bahwa konsumen pada saat ini tidak terlalu mementingkan estetika suatu produk, tetapi konsumen lebih mementingkan apakah harga yang dibayar sesuai dengan manfaat, kualitas, dan kinerja, dan juga tergantung apakah sikap konsumen terhadap suatu merek positif atau tidak positif. Jadi sebaik apapun estetika dari iPhone dari sisi desain, warna, bentuk, tekstur/sentuhan, dan keindahan, tidak akan mempengaruhi minat beli konsumen.

Pada hasil pengujian hipotesis kedua $\left(\mathrm{H}_{2}\right)$ menunjukkan bahwa sikap terhadap merek merupakan prediktor positif untuk niat pembelian. Hasil pengujian hipotesis ini sejalan dengan penelitian yang dilakukan oleh Ghorban (2012), Kudeshia \& Kumar (2017), dan Park et al. (2015) menyatakan bahwa sikap konsumen terhadap suatu merek dapat mempengaruhi minat beli seseorang. Sikap terhadap merek sendiri merupakan evaluasi keseluruhan konsumen terhadap suatu merek dalam hal kualitas dan kepuasan yang dirasakan oleh konsumen. Jadi jika sikap konsumen terhadap suatu merek baik, maka akan ada probabilitas untuk meningkatkan minat beli seseorang dalam membeli suatu produk. Minat beli suatu produk juga akan semakin tinggi apabila sikap konsumen terhadap suatu merek itu baik dari segi atribut dan manfaat spesifik dari suatu merek tersebut. Seperti yang disebutkan sebelumnya, iPhone merupakan perangkat smartphone yang terkenal. Jadi jika sikap konsumen terhadap merek positif, maka konsumen akan menganggap produk 
dari merek tersebut layak untuk dibeli, sehingga akan ada probabilitas konsumen akan membeli iPhone di masa yang akan mendatang.

Pada hasil pengujian hipotesis ketiga $\left(\mathrm{H}_{3}\right)$ menunjukkan bahwa persepsi harga merupakan prediktor positif untuk niat pembelian. Hasil pengujian hipotesis ini sejalan dengan penelitian yang dilakukan oleh Prawira \& Yasa (2014), Ivoni et al. (2015), dan Lien et al. (2015) menyatakan bahwa persepsi harga memiliki pengaruh positif terhadap niat pembelian. Persepsi harga sendiri merupakan persepsi jumlah harga yang ditawarkan terhadap manfaat yang diperoleh. Hal ini menunjukkan bahwa persepsi harga yang baik dapat membangun minat beli suatu produk. Seperti yang disebutkan sebelumnya, harga iPhone yang ditawarkan oleh produsen iPhone cukup tinggi. Jadi, persepsi konsumen terhadap harga yang ditawarkan juga tergantung dari konsumen itu sendiri. Jika persepsi konsumen terhadap harga yang diterima baik, maka konsumen akan menganggap harga yang diterima sesuai dengan kualitas, manfaat, dan kinerja, sehingga akan ada kemungkinan dapat meningkatkan minat beli seseorang dalam membeli iPhone.

\section{PENUTUP}

Berdasarkan analisis hipotesis yang telah dilakukan, dapat disimpulkan bahwa sikap terhadap merek dan persepsi harga merupakan prediktor positif untuk niat pembelian, tetapi estetika bukan merupakan prediktor positif untuk niat pembelian.

Penelitian ini memiliki keterbatasan yaitu jumlah sampel yang diteliti masih terbatas yaitu sebanyak 100 orang, sampel masih sebatas mahasiswa FEB UNTAR, variabel yang diteliti masih sebatas estetika, sikap terhadap merek, persepsi harga, dan niat pembelian, dan masih ada beberapa kekeliruan dalam penulisan, serta menganalisis variabel yang terkait dalam penelitian ini.

Beberapa saran untuk penelitian selanjutnya adalah agar dapat menggunakan jumlah sampel yang lebih dari 100 orang, dapat memperluas ruang lingkup sampel yang digunakan, dan agar dapat menambah variabel atau mengganti variabel yang lainnya (yang memiliki pengaruh lebih besar terhadap niat pembelian) selain variabel yang digunakan pada penelitian ini.

Sikap terhadap merek memegang peranan paling penting dalam niat pembelian sebuah produk dari Apple, yaitu iPhone. Peneliti menyarankan bahwa produsen iPhone (Apple) harus menjaga kepercayaan konsumen terhadap Apple dengan memperhatikan dan meningkatkan kinerja suatu produk, agar produk tersebut makin dipercayai memiliki kinerja yang baik oleh konsumen, sehingga menimbulkan sikap konsumen yang positif terhadap suatu merek, dengan demikian akan ada kemungkinan dapat meningkatkan niat pembelian seseorang untuk membeli iPhone.

Selain sikap terhadap merek, persepsi harga juga memegang peranan penting dalam niat pembelian sebuah produk Apple, yaitu iPhone. Peneliti juga menyarankan bahwa produsen iPhone (Apple) sebaiknya memberikan potongan harga berupa diskon, agar harga yang ditawarkan sedikit lebih terjangkau, sehingga persepsi konsumen terhadap harga dapat diterima baik oleh konsumen, dengan demikian akan ada kemungkinan dapat meningkatkan niat pembelian seseorang untuk membeli iPhone. 


\section{DAFTAR PUSTAKA}

Apple.Inc. (2009). “Apple Reports Second Quarter Results”. Retrieved (October 2019) from http://www.apple.com/pr/library/2009/04/22results.html

Chen, B. X. (2010). "iPhone Wins Phone Popularity Contest, Android Dominates OS". Retrieved (October 2019) from https://www.wired.com/2010/11/iphone-androidmarketshare/

Garson, G. D. (2016). Partial Least Squares: Regression and Structural Equation Models. Asheboro, NC: Statistical Associates Publishers.

Ghorban, Z. S. (2012). Brand attitude, its antecedents and consequences. Investigation into smartphone brands in Malaysia. Journal of Business and Management, 2(3), 31-35.

Gibbs, S. (2018, August 1). "Huawei beats Apple to become second-largest smartphone maker". $\quad$ Retrieved (October 2019) from https://www.theguardian.com/technology/2018/aug/01/huawei-beats-applesmartphone-manufacturer-samsung-iphone

Ha-Brookshire, J. and Yoon, S. (2012), "Country of origin factors influencing US consumers' perceived price for multinational products", Journal of Consumer Marketing, 29(6), 445-454.

Hair Jr, J. F., Sarstedt, M., Hopkins, L., \& G. Kuppelwieser, V. (2014). Partial least squares structural equation modeling (PLS-SEM) An emerging tool in business research. European Business Review, 26(2), 106-121.

Ho, C. H., \& Wu, T. Y. (2012). Factors affecting intent to purchase virtual goods in online games. International Journal of Electronic Business Management, 10(3), 204-212.

Ibrahim, I. I., Subari, K. A., Kassim, K. M., \& Mohamood, S. K. B. (2013). Antecedent stirring purchase intention of Smartphone among adolescents in Perlis. International Journal of Academic Research in Business and Social Sciences, 3(12), 84-97.

Ivoni, D., Santika, I. W., \& Suryani, A. (2015). Pengaruh Persepsi Harga, Orientasi Merek, dan Orientasi Belanja Terhadap Niat Beli Fashion Online. E-Jurnal Manajemen Unud, 4(4), 898-911.

Kim, H. W., Gupta, S., \& Koh, J. (2011). Investigating the intention to purchase digital items in social networking communities: A customer value perspective. Information \& Management, 48(6), 228-234.

Kompas Cyber Media. (2019, November 28). "Resmi, Ini Daftar Harga iPhone 11, 11 Pro, dan 11 Pro Max di Indonesia". Retrieved (December 2019) from https://tekno.kompas.com/read/2019/11/28/09070067/resmi-ini-daftar-harga-iphone11-11-pro-dan-11-pro-max-di-indonesia

Kudeshia, C., \& Kumar, A. (2017). Social eWOM: does it affect the brand attitude and purchase intention of brands? Management Research Review, 40(3), 310-330.

Lien, C. H., Wen, M. J., Huang, L. C., \& Wu, K. L. (2015). Online hotel booking: The effects of brand image, price, trust and value on purchase intentions. Asia Pacific Management Review, 20(4), 210-218.

Naing, K. W., \& Chaipoopirutana, S. (2014). The factors affecting purchase intention of a smart phone in yangon, Myanmar. In International Conference on Trends in Economics, Humanities and Management, 14(2), 190-194.

Nurtjahjanti, H. (2012). Hubungan antara Persepsi terhadap Harga dan Kualitas Produk dengan Minat Membeli produk fashion online shop di facebook pada mahasiswa Politeknik X Semarang, 11(2). 
Park, H. H., Jeon, J. O., \& Sullivan, P. (2015). How does visual merchandising in fashion retail stores affect consumers' brand attitude and purchase intention? The International Review of Retail, Distribution and Consumer Research, 25(1), 87-104.

Prawira, B., \& Yasa, N. N. K. (2014). Pengaruh Kualitas Produk, Citra Merek Dan Persepsi Harga Terhadap Minat Beli Produk Smartphone Samsung Di Kota Denpasar. E-Jurnal Manajemen, 3(12), 3642-3658.

Reuters. (2019, July 31). "Penjualan iPhone Anjlok Tertinggi Sepanjang Tujuh Tahun". Retrieved from

(October https://www.cnnindonesia.com/teknologi/20190731141228-185417096/penjualaniphone-anjlok-tertinggi-sepanjang-tujuh-tahun

Santoso, J. F. (2014). Pengaruh perceived quality terhadap attitude toward brand pada pengguna smartphone samsung di surabaya. Jurnal Strategi Pemasaran, 2(1), 1-7.

Semuel, H., \& Lianto, A. S. (2014). Analisis ewom, brand image, brand trust dan minat beli produk smartphone di Surabaya. Jurnal Manajemen Pemasaran, 8(2), 7-54.

Shaharudin, M. R., Mansor, S. W., Hassan, A. A., Omar, M. W., \& Harun, E. H. (2011). The relationship between product quality and purchase intention: The case of Malaysia's national motorcycle/scooter manufacturer. African Journal of Business Management, 5(20), 8163-8176.

Sumaedi, S., Bakit, I. G. M. Y., \& Metasari, N. (2011). The effect of students' perceived service quality and perceived price on student satisfaction. Management Science and Engineering, 5(1), 88-97.

Swilley, E. (2012). Aesthetic technology: scale development and measurement. International Journal of Technology Marketing, 7(3), 324-341.

Ting, D. H., Lim, S. F., Patanmacia, T. S., Low, C. G., \& Ker, G. C. (2011). Dependency on smartphone and the impact on purchase behaviour. Young Consumers: Insight and Ideas for Responsible Marketers, 12(3), 193-203.

Toufani, S., Stanton, J. P., \& Chikweche, T. (2017). The importance of aesthetics on customers' intentions to purchase smartphones. Marketing Intelligence \& Planning, 35(3), 316-338.

Wang, Y. J., Minor, M. S., \& Wei, J. (2011). Aesthetics and the online shopping environment: Understanding consumer responses. Journal of Retailing, 87(1), 46-58.

Wu, P. and Wang, Y. (2011), "The influences of electronic word-of-mouth message appeal and message source credibility on brand attitude", Asia Pacific Journal of Marketing and Logistics, 23(4), 448-472.

Zietsman, M., Mostert, P. and Svensson, G. (2019), "Perceived price and service quality as mediators between price fairness and perceived value in business banking relationships", International Journal of Bank Marketing, 37(1), 2-19. 